\title{
Approaches for Aggregating Preferences in Participatory Forest Planning - An Experimental Study
}

\author{
Eva-Maria Nordström", Karin Öhman and Ljusk Ola Eriksson
}

\author{
Department of Forest Resource Management, Swedish University of Agricultural Sciences (SLU), SE-901 83 Umeå, \\ Sweden
}

\begin{abstract}
Many forest planning situations are complex; multiple criteria of different natures have to be considered and several stakeholders or social groups may be involved. An approach that is increasingly used in these complex situations is the combination of multiple criteria decision analysis (MCDA) and participatory planning. A crucial part of MCDA processes involving more than one decision maker is the aggregation of individual stakeholder preferences into a collective preference; in a participatory context, the aggregation mechanism should be equitable and transparent so as to create trust in the process. This study evaluates three approaches for the aggregation of stakeholders' preferences in a participatory MCDA process: extended goal programming (EGP), the weighted arithmetic mean method (WAMM), and the geometric mean method (GMM). The aggregation approaches were tested in a role playing exercise with students. The approaches have different properties and result in different rankings, thus the main conclusions are that the choice of aggregation approach should depend on the situation and the stakeholders. Moreover, if aggregation methods are used in participatory planning, they should be used as tools for exploring and increasing knowledge about the issue rather than as methods that produce "the optimal solution".
\end{abstract}

Keywords: Analytic hierarchy process, extended goal programming, forest management, geometric mean method, multiple criteria decision analysis, weighted arithmetic mean method.

\section{INTRODUCTION}

Forest planning has mainly been focused on timber production. However, during the last decades the importance of nontimber forest values has been increasingly recognized. In many situations the value of forests cannot be considered purely in economic terms, and additional interests must be considered, such as conserving biodiversity and providing possibilities for recreation. This results in planning situations where a multiplicity of criteria of very different natures has to be considered, often involving several stakeholders or social groups, implicating the need for new methods of planning.

An approach that has been proposed is the combination of multiple criteria decision analysis (MCDA) and participatory planning. In the forestry context, approaches combining participatory planning and MCDA are relatively new [1]; most studies of participatory forest planning in combination with MCDA techniques have been published during the past decade [2-11].

Participation can be defined as "a voluntary process whereby people, individually or through organized groups, can exchange information, express opinions and articulate interests, and have the potential to influence decisions or the outcome of the matter at hand" [12]. This study concerns participatory forest planning, a term which is used in the sense of a forest planning process that involves not only the

Address correspondence to this author at the Department of Forest Resource Management, Swedish University of Agricultural Sciences (SLU), SE-901 83 Umeå, Sweden; Tel: +46 907868258 ;

E-mail: Eva-Maria.Nordstrom@slu.se forest owners who commonly are the decision makers, but also stakeholders that have a vested interest in the planning process and the outcome of the process. These stakeholders may be representatives from governmental institutions and other organizations, such as companies and nongovernmental organizations. Stakeholders may also take part in the planning process through direct public participation as individuals. The goal of the participatory forest planning process is to identify or create a forest plan which incorporates stakeholder values.

MCDA is a set of techniques that can be used to support decision making in complex situations where there are different and conflicting interests. MCDA provides a structured way of working that generates knowledge about the problem and about the objectives of the different stakeholders [13]. Furthermore, MCDA can support a participatory process in making it transparent, fair, and understandable, which are all important properties for the process to be considered legitimate and accepted by the stakeholders [14]. Transparency means that it is possible to account for the outcome of the process in terms of the input and the mechanisms of the MCDA technique, because the MCDA process is well structured [15]. Fairness has to do with the power relations between stakeholders and how power differences are handled in the process [16]. With MCDA, the influence of different stakeholders on the outcome can be made explicit in the aggregation of preferences [14].

Thus, a crucial part of any MCDA process when there is more than one decision maker is the aggregation of individual stakeholder preferences into a collective preference [17]. Belton and Pictet [18] defined three general 
procedures for achieving a group decision: (i) sharing-the group acts as a single decision maker and agrees on one common preference; (ii) aggregating - the stakeholders state their individual preferences and a common preference is obtained through voting or calculation; and (iii) comparing - the stakeholders state their individual preferences and these are used in a negotiation process where the aim is to find a consensus solution [14]. In the procedures for sharing and comparing, a consensus is sought via discussions and negotiations. When aggregation is employed, deliberations among stakeholders are to some extent replaced by a mechanistic approach to find consensus. In most studies combining MCDA and participatory forest planning, the overall results have been calculated through aggregation in this sense of the word [e.g., 6, 9, 19, 20].

The analytic hierarchy process (AHP) [21], in its standard form or combined with other MCDA methods, is one of the most frequently used MCDA methods in forestry applications $[1,22]$. The combination of the AHP and participatory planning has been applied in real-world forest planning cases on strategic and large-scale levels, showing the AHP to be a useful tool in participatory forest planning $[3,19,23,24]$.

A main advantage of AHP is that the pairwise comparison procedure helps the decision maker to focus on only two elements at a time. In addition, the pairwise comparisons can help decision makers better understand the decision problem [25]. However, pairwise comparison may be more difficult for decision makers to implement than other more straightforward methods such as point allocation or rating; furthermore, the pairwise comparisons will be very burdensome if there are many criteria and alternatives involved. Five to nine (seven \pm two) objects have been proposed as the maximum number of objects that a person can compare and still be consistent in judgment [21]. Other issues that have been raised as potentially problematic are (i) the adequacy of the preference scale used in comparisons, (ii) how the decision problem is structured, (iii) how the pairwise comparison is carried out, and (iv) how stakeholders are weighted to influence the outcome [3, 24]. This study primarily addresses the question of how stakeholder weights and, furthermore, how aggregation methods influence the outcome.

For the AHP, two common methods for aggregation of individual preferences are the geometric mean method (GMM) and the weighted arithmetic mean method (WAMM) [26]. The mathematical properties of these methods have been debated [26-28], and a number of alternative aggregation methods have been proposed [29-32]. In a participatory context, it is crucial that the aggregation mechanism be not only methodologically sound but also equitable and transparent to create trust in this kind of process $[11,17]$.

In view of this, an aggregation method based upon the determination of cardinal compromise consensus, extended goal programming (EGP), proposed by González-Pachón and Romero [32] has interesting properties. The method can generate solutions for consensus based on the majority principle, for consensus based on minimizing the disagreement of the most displaced stakeholder, and for intermediate consensus that balances the majority and minority views. Thus, the solutions have a clear preferential interpretation, because they are not only determined by the relative weights of influence of the different stakeholders, as is the case with WAMM and GMM, but also by balancing the point of view of the majority against the view of the minority. Consequently, the EGP approach can make the aggregation procedure both transparent and equitable if the process is well managed.

González-Pachón and Romero [32] have described three main ways of applying EGP to an aggregation problem: (i) In the traditional aggregation formulation when using AHP, criteria weights are first established from each of the individual pairwise comparison matrices and are then aggregated; (ii) when the group wants to act as a unit, the individual pairwise comparison matrices are aggregated into a consensus matrix from which common criteria weights are established; and (iii) when the members of the group want to act as individuals, common criteria weights are established directly from the individual pairwise comparison matrices. There are a number of studies where EGP has been used for aggregation. The first variant, the traditional aggregation formulation, has been tested in an energy planning case study [33]. Using AHP, a number of stakeholders from four social groups stated their preferences for five different criteria defining an electricity planning model and criteria weights were established for each stakeholder. The individual criteria weights were then aggregated for each social group using weighted goal programming. Finally, EGP was used to aggregate the criteria weights of the four social groups into common criteria weights. The second variant, where the group acts as a unit, has also been applied in two different case studies. In the first case, forestry students made pairwise comparisons of four criteria: biodiversity, net carbon captured, veneer volume, and net present value [34]. The individual pairwise comparison matrices were aggregated, producing several alternative consensus matrices representing different compromise solutions between the majority and the minority view. The criteria weights established from these matrices were to be used in creating a management model for two public forests. In a second case, a participatory forest planning process, the stakeholders were grouped into four social groups with different sets of criteria [35]. Consensus matrices were produced for each social group and criteria weights were established from these matrices. The criteria weights were then used to establish rankings for a number of forest plan alternatives. Finally, the rankings of alternatives for each social group were combined to produce aggregated rankings of the alternatives. However, none of these studies compare the outcome of EGP with other aggregation methods.

In this study, the first variant of EGP is compared with two other approaches for aggregation of stakeholders' preferences in a participatory MCDA process: the WAMM and the GMM. The approaches are tested in case study based on a role playing exercise involving master students, where the task was to aggregate the preferences of several stakeholders to produce a ranking of five forest plan alternatives. The study evaluates the results and properties of the different approaches. In addition, a group preference approach is used as a reference for comparison. The 
reference is, however, a procedure of sharing rather than an aggregation method within the definition of Belton and Pictet [18].

\section{METHODS}

\section{Analytic Hierarchy Process}

The standard procedure of the AHP for a single decision maker can be described in three steps:

1. The decision maker determines his/her preferences by pairwise comparisons of criteria using Saaty's ninepoint ratio scale $[21,36]$. Similarly, for each criterion, the decision maker compares the different alternatives. The comparisons provide square matrices of preference values.

2. Weights for criteria and alternatives are determined from the preference matrices using the eigenvalue technique; that is, the eigenvector corresponding to the largest eigenvalue is found for each pairwise comparison matrix.

3. The overall priority of each alternative is calculated by multiplying the weight of the criterion with the weight of the alternative with respect to the criterion in question. This is done for all criteria; the resulting products are summed to produce the overall weight of the alternative.

However, in a participatory situation, the preferences of the different stakeholders have to be aggregated to produce a common ranking of alternatives. The aggregated rankings are hereafter referred to as consensus rankings. This term is adopted for convenience and does not imply that all stakeholders agree completely with the rankings.

In the following subsections, the WAMM, GMM and EGP as aggregation methods are presented briefly. They all share

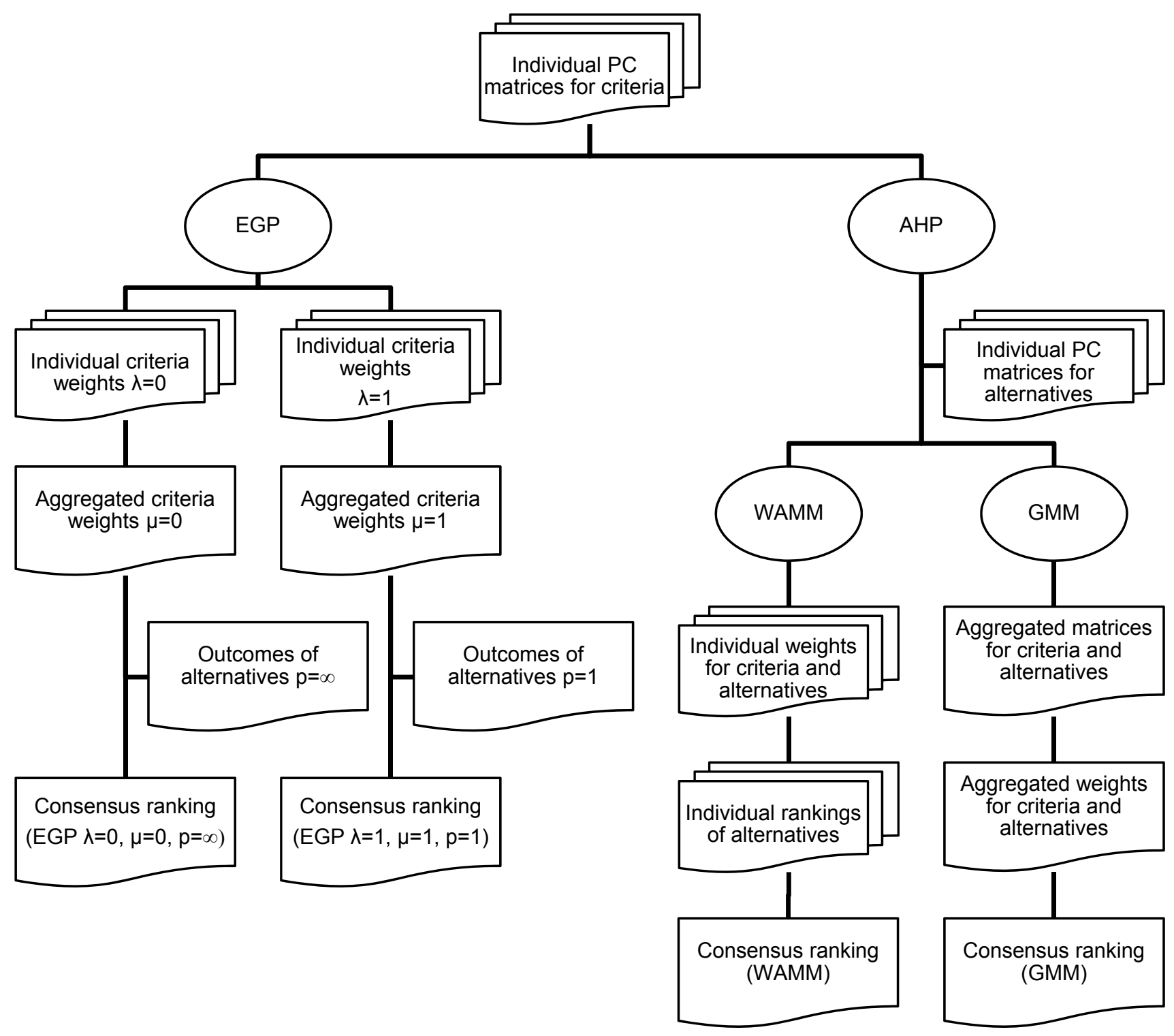

Fig. (1). Overview of the inputs and outputs of the different approaches for the aggregation of preferences. Ovals indicate methods, multipledocument icons indicate individual preferences of multiple stakeholders, and single-document icons indicate preferences that are aggregated for or common to all stakeholders. ( $\mathrm{PC}=$ pairwise comparison). 
the same two initial steps of the AHP. The main differences between the WAMM and GMM and the EGP approach tested in this paper are (i) that in the WAMM and GMM, criteria weights are derived through the AHP (eigenvalue technique), whereas the calculation of criteria weights is part of the EGP approach, and (ii) that the WAMM and GMM involve the stakeholders in pairwise comparison of the alternatives for each criterion, resulting in matrices and weights for not only criteria but also alternatives, whereas in the EGP approach, this step is replaced by calculations of normalized outcomes of alternatives that do not require stakeholder input. Fig. (1) is an overview of the inputs and outputs of the different methods, which are described in more detail in sections 2.2 and 2.3.

\section{Weighted Arithmetic Mean Method and Geometric Mean Method}

In the WAMM, global priorities for alternatives are calculated for each individual and then a consensus ranking is determined by calculating the weighted arithmetic mean for the global priority of each alternative, using the weights of influence determined for the stakeholders:

$\frac{1}{k} \sum_{t=1}^{k} W^{t} A_{s}^{t}$

where there are $t=1,2, \ldots, k$ individual stakeholders and $\mathrm{s}=$ $1,2, \ldots, r$ alternatives. $A_{s}^{t} \in[0,1]$ is the global priority of alternative $s$ calculated for stakeholder $t$, and $W^{t}$ is the weight of the influence of stakeholder $t$.

In the GMM, the geometric mean of the judgments of all stakeholders for each element in the pairwise comparison matrices is calculated:

$$
\left(\prod_{t=1}^{k} m_{i j}^{t}\right)^{1 / k} \forall i, j,
$$

where $m_{i j}^{t}$ is the element in the pairwise comparison matrix for stakeholder $t$ when criterion $i(i=1,2, \ldots, q)$ is compared with criterion $j$. Similarly, the geometric means of the judgments of all stakeholders are calculated from the matrices, where alternatives are compared for each criterion:

$$
\left(\prod_{t=1}^{k} m_{s v}^{t i}\right)^{1 / k} \forall s, v \text {, }
$$

where $m_{s v}^{t i}$ is the element in the pairwise comparison matrix for stakeholder $t$ when alternative $s$ is compared with alternative $v$ for criterion $i$.

The result is one matrix with aggregated preferences for the criteria and $q$ matrices with aggregated preferences for the alternatives in terms of each criterion. Weights for criteria and alternatives are then determined from these matrices.

\section{Extended Goal Programming}

Goal programming (GP) is a method of decision analysis that deals with problems where target levels can be assigned to the attributes and where the nonachievement of the corresponding goals is minimized [37]. How this nonachievement is measured depends on the specific GP approach that is used. Two common GP approaches are weighted (or Archimedean) GP and MINMAX (or Chebyshev) GP. Weighted GP can be interpreted as the maximization of a separable and additive utility function. In a participatory context, this could be interpreted such that the solution obtained is the best from the point of view of the majority. MINMAX GP, on the other hand, involves the optimization of a utility function where the maximum deviation is minimized, which means that the solution obtained is the best from the point of view of the minority or the "worst-off individual" [38, 39].

The EGP method combines the weighted and MINMAX formulations and makes it possible to find compromise solutions [32]. This is done by introducing a user-defined control parameter $(\lambda, \mu)$ that regulates the trade-off between the point of view of the majority $(\lambda$ or $\mu=1)$ and the point of view of the minority or the worst-off individual $(\lambda$ or $\mu=0)$. The control parameter $\lambda$ is used in the first step of the approach and $\mu$ in the second step, but they serve a similar purpose. The method is adapted to the present study and includes not only the aggregation of individual preferences into a common preference (Model 2) but also the calculation of criteria weights from the preference matrices (Model 1) and determination of the partial weights for the alternatives (Equation 16). In EGP, therefore, the evaluation of alternatives for each criterion is made using a kind of value function. For this procedure, two important assumptions are made: (i) that the value functions are linear (that is, for a criterion that is to be maximized, more is always better and a unit is worth just as much independent of where it is located on the scale) and (ii) that the range for each criterion is local (that is, the alternative that performs worst for a certain criterion is the bottom end of the range for this criterion whereas the best alternative is the top end of the range).

The method comprises the following three steps [39].

\section{Determination of Criteria Weights for Each Stakeholder}

Preferences in the form of pairwise comparisons of $i=$ $1,2, \ldots, q$ criteria are stated by $t=1,2, \ldots, k$ individual stakeholders to establish a ranking of $s=1,2, \ldots, r$ alternatives. The starting point is constructing pairwise comparison matrices of the individual stakeholders. Weights for the criteria are determined for each individual $t$ by solving the following EGP model.

\section{Model 1}

Achievement Function

$\operatorname{Min}(1-\lambda) D+\lambda\left[\sum_{\substack{i=1 \\ j}}^{q} \sum_{\substack{j \neq 1 \\ j \neq i}}^{q}\left(n_{i j}^{t}+p_{i j}^{t}\right)\right]$

subject to

$\underline{\text { Goals and Constraints }}$

$m_{i j}^{t} w_{j}^{t}-w_{i}^{t}+n_{i j}^{t}-p_{i j}^{t}=0, i, j \in\{1, \ldots, q\}$ 
$\sum_{i=1}^{q} \sum_{\substack{j=1 \\ j \neq i}}^{q}\left(n_{i j}^{t}+p_{i j}^{t}\right)-D \leq 0$

$\sum_{i=1}^{q} w_{i}^{t}=1$

$n_{i j}^{t} \geq 0, p_{i j}^{t} \geq 0$,

$\lambda \in[0,1] \quad$ (user-defined control parameter),

where $m_{i j}^{t}$, as in equation (2), is the judgment made for criterion $i$ compared with criterion $j$, and $w_{i}^{t}$ is the weight of criterion $i$ for stakeholder $t . D$ is the maximum deviation of any judgment from the established criteria weights. The negative and positive deviation variables are denoted by $n_{i j}^{t}$ and $p_{i j}^{t}$. The parameter $\lambda$ is a user-defined control parameter that can be set to any value between 0 and $1 ; \lambda=1$ gives an Archimedean GP model while $\lambda=0$ gives a MINMAX GP model, and intermediate values yield compromise solutions.

\section{Aggregation of Individual Criteria Weights}

Next, the criteria weights for each individual stakeholder $t$ are aggregated into a set of criteria weights common to all stakeholders. This is done by applying the following model.

\section{Model 2}

$\underline{\text { Achievement Function }}$

$\operatorname{Min}(1-\mu) D+\mu\left[W^{t} \sum_{t=1}^{k} \sum_{i=1}^{q}\left(n_{i}^{t}+p_{i}^{t}\right)\right]$

subject to

Goals and Constraints

$w_{i}^{c}+n_{i}^{t}-p_{i}^{t}=w_{i}^{t}, i \in\{1, \ldots, q\}, t \in\{1, \ldots, k\}$,

$W^{t} \sum_{i=1}^{q} \sum_{t=1}^{k}\left(n_{i}^{t}+p_{i}^{t}\right)-D \leq 0$,

$\sum_{i=1}^{q} w_{i}^{c}=1$

$n \geq 0, p \geq 0$,

$\mu \in[0,1]$ (user-defined control parameter),

where $w_{i}^{t}$ is the weight of criterion $i$ for stakeholder $t$ from the solution of Model 1 , and $n_{i}^{t}$ and $p_{i}^{t}$ are the negative and positive deviation variables for criterion $i$ and stakeholder $t$. The aggregated weight of criterion $i$ is denoted by $w_{i}^{c}$ and the weight of influence for stakeholder $t$ is denoted by $W^{t}$. The parameter $\mu$ is analogous to parameter $\lambda$ in Model 1 .

\section{Determination of Consensus Rankings of Alternatives}

To determine consensus rankings of alternatives, criteria weights need to be combined with the outcomes of the different alternatives. However, the outcomes are measured for different entities and have to be normalized to be comparable. The normalization is:

$N_{s}^{i}=\frac{O^{i^{*}}-O_{s}^{i}}{O^{i^{*}}-O_{*}^{i}}$,

where $O^{i *}$ and $O_{*}^{i}$ are the ideal and anti-ideal values, respectively, for the $i$ th criterion within the set of alternatives $(s), O_{s}^{i}$ is the outcome that corresponds to the $s$ th alternative when evaluated according to the $i$ th criterion, and $N_{s}^{i}$ is the normalized outcome. With this normalization procedure, the normalized outcomes are expressed as distances from the ideal value and all outcomes are in the range between 0 (ideal/best value) and 1 (anti-ideal/worst value).

Consensus rankings of the alternatives can be obtained by two opposing approaches that employ different norms or definitions of distance. First, the best consensus ranking is determined by maximizing the weighted average of the outcomes. This is done by applying:

$$
\left(A_{s}\right)_{p=1}=\sum_{i=1}^{q} w_{i}^{c} N_{s}^{i}
$$

where $\left(A_{s}\right)_{p=1}$ is the overall priority for the $s$ th alternative when the norm $p=1$ is used. Second, the best consensus ranking from the point of view of minimizing the most displaced result is established. This is obtained by applying:

$$
\left(A_{s}\right)_{p=\infty}=\operatorname{MAX}_{\forall i}\left[w_{i}^{c} N_{s}^{i}\right] \text {, }
$$

where $\left(A_{s}\right)_{p=\infty}$ is the overall priority for the $s$ th alternative plan when the norm $p=\infty$ is used.

The parameters $(\lambda, \mu)$ and $p$ play a crucial role in the different models of the approach described here. The parameter $p$ is, mathematically speaking, a metric that defines the family of distance functions. From a preferential point of view, $p$ plays the role of a "balancing factor" between the "group utility" or "majority principle" obtained for $p=1$ and the "maximum discrepancy" or "minority principle" obtained for $p=\infty$. (See [40] for a discussion of the preferential properties underlying metric $p$.) The control parameters $(\lambda, \mu)$ can be interpreted in a similar way, as trade-offs or marginal rates of substitution between the "group utility" and the "utility of the stakeholder most displaced with respect to the consensus obtained". The parameters $(\lambda, \mu)$ and $p$ should correspond to the kind of consensus that is suitable for the situation; in a participatory process, stakeholders may be involved in setting the values of the parameters. For a thorough study of the relationships between control parameters $(\lambda, \mu)$ and metric $p$ within a compromise programming context, see [41]. 


\section{CASE STUDY}

\section{Experiment Setup}

A participatory process was simulated through role-play with master students at the Swedish University of Agricultural Sciences. The students were enrolled in a course on forest landscape multiple-use management. The course was an optional course on advanced level involving students with either forest management or forest ecology as major subjects and the role playing exercise was part of the course work. Before the role-play began, the students received basic information on role-playing techniques. At the start of the role-play, the students were divided into two groups. The six students in the first group were instructed to state their preferences individually. As a reference group to compare with, the five students in the other group were instructed to work together as a group to establish a collective preference directly through discussion. Next, the groups were presented with a scenario for the role-play. The scenario was based on a real case study in progress in the municipality of Lycksele in northern Sweden [14, 42]. The following is a summary of the scenario presented to the students [39]. The town of Lycksele is the regional centre in a forest area where commercial forestry is an important industry for the local economy. However, the forest around the town holds other values and is important to the inhabitants of the town for reasons other than wood production; e.g., there are interests in preserving biodiversity and providing forest suitable for recreation. Thus, the municipality has initiated a project with the goal to produce a multiple-use forest management plan for an area of approximately 10,000 hectares. The planning process in the role-play was designed as a participatory process where the forest company and the municipality together with the representatives of three interest groups were to choose a multiple-use forest management plan from five alternatives. Thus, there were five different roles: the municipality ecologist, the tourism entrepreneur, the forest company representative (two students in the first group were assigned this role, since there were five roles but six students), the nature conservationist, and the representative for sport and outdoor life. Each role was characterized by a brief description and the roles were assigned to the students to fit their major subjects and general interests. The next step in the role-play was that the students were presented with an objective hierarchy (Fig. 2) and the five forest management plans.

The hierarchy was constructed prior to the role-play session. The hierarchy was based on the background information of the Lycksele case and constructed with consideration of the desired properties of a fundamental objective hierarchy [39, 43]. The performance of the alternatives was evaluated in terms of the following lowestlevel criteria.

- $\quad$ Economic profitability: net present value (NPV) in units of millions of Swedish crowns (mill. SEK)

- $\quad$ Standing volume at the end of the last period: volume in units of cubic meters $\left(\mathrm{m}^{3}\right)$

- $\quad$ Species dependent on dead wood: information presented for both 1) volume left after harvesting in units of percent (\%), and 2) area of forest with no treatment or management for nature conservation in units of hectares (ha)

- $\quad$ Species with low dispersal capacity: area of forest with no treatment or management for nature conservation in units of hectares (ha)

- $\quad$ Species with high dispersal capacity: area of forest older than 100 years at the end of the last period in units of hectares (ha)

- Accessibility to the forest ${ }^{1}$ : information presented for both 1) volume left after harvesting in units of percent $(\%)$, and 2) area of forest with management for social or recreational values in units of hectares (ha)

- Clear-cut area: average for all periods in units of hectares (ha)

- Area of recreational forest: area of forest with management for social or recreational values in units of hectares (ha)

The five forest plan alternatives (referred to as A, B, C, $\mathrm{D}$, and E) were presented to the students in the form of tables, diagrams, and maps. The forest plans had various strategic focuses: timber production (A), biodiversity (B), recreation $(C)$, and different mixtures of these interests (D and E). The plans are summarized in Table $\mathbf{1}$.

The students in the first group made pairwise comparisons individually of the criteria (seven comparisons) and alternatives (ten comparisons per lowest-level criteria, for each of the eight lowest-level criteria). Afterward, the group members discussed and together made pairwise comparisons to determine the relative importance of each stakeholder. From the pairwise comparisons made by the group, the following weights of influence of the different stakeholders were obtained (hereafter referred to as the stakeholder weights):

- The municipality ecologist: 0.23

- $\quad$ The tourism entrepreneur: 0.18

- The forest company representative: 0.31

- The nature conservationist: 0.09

- The representative for sport and outdoor life: 0.19

The reference group made all pairwise comparisons together in a group discussion. Both groups used a Microsoft Excel worksheet that was developed to elicit preferences through a pairwise comparison procedure, in line with the AHP. The standard AHP was used to obtain criteria weights and weights of alternatives when using the WAMM and GMM as aggregation methods. When using EGP, criteria weights were obtained using Model 1 described in section

\footnotetext{
1"Accessibility" means in this case how inviting the forest is for recreational users in terms of how nice and easy it is to walk in the forest. Thus, the indicators used are 1) harvest residues as in "volume left after harvesting" of which less is better, and 2) area suitable for recreation as in "area of forest with management for social or recreational values" of which more is better. Thus, we have to keep in mind that the criterion "Accessibility" is partly dependent on the criterion "Area of recreational forest", and partly inversely dependent on "Species dependent on dead wood". Furthermore, "Accessibility" as it is defined here should not be confused with an accessibility criterion expressing spatial relationships like, e.g., distance to road or distance to areas where people are living.
} 


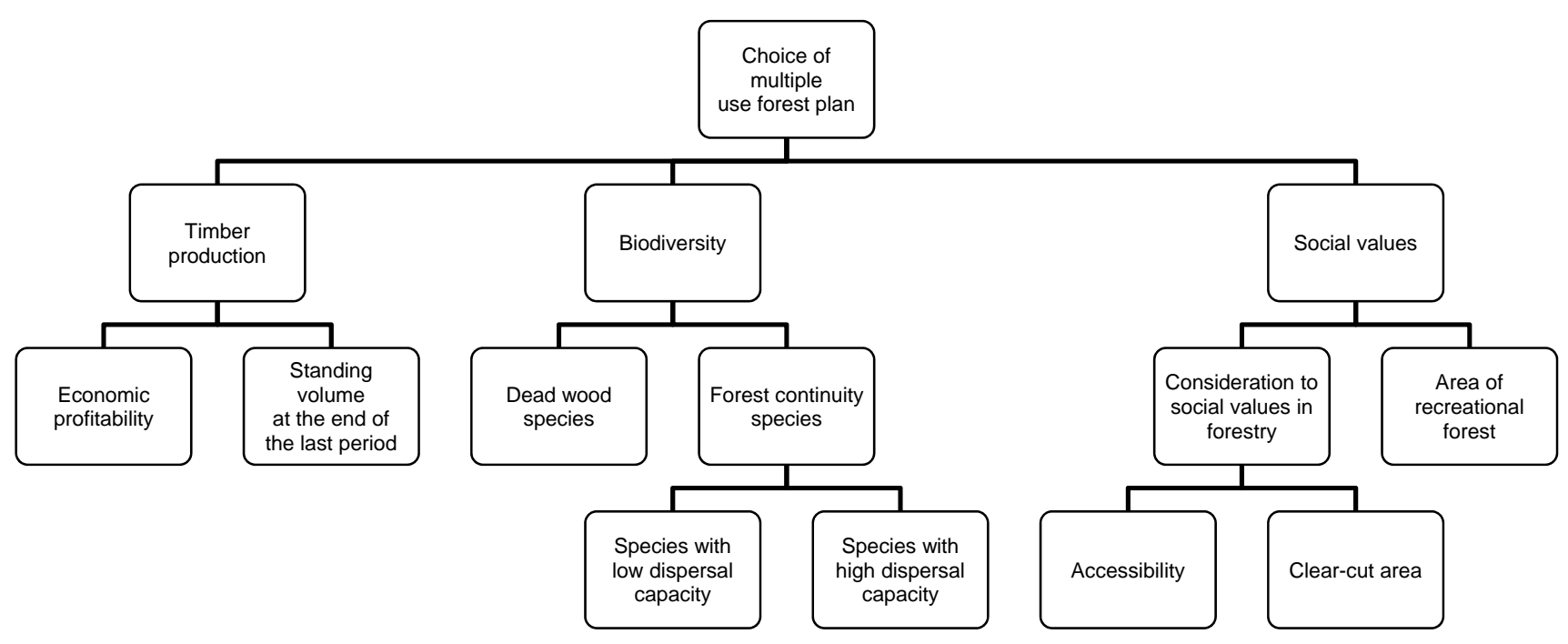

Fig. (2). The objective hierarchy of the case study.

Table 1. Summary of the Five Forest Plan Alternatives

\begin{tabular}{|c|c|c|c|c|c|}
\hline & $\begin{array}{c}\text { A } \\
\text { Timber Production }\end{array}$ & $\begin{array}{c}\text { B } \\
\text { Biodiversity }\end{array}$ & $\begin{array}{c}\text { C } \\
\text { Recreation }\end{array}$ & $\begin{array}{c}\text { D } \\
\text { Mixed } 1\end{array}$ & $\begin{array}{c}E \\
\text { Mixed 2 }\end{array}$ \\
\hline NPV (mill. SEK) & 80.0 & 62.2 & 64.4 & 74.7 & 66.0 \\
\hline Standing volume $\left(\mathrm{m}^{3}\right)$ & 720500 & 762000 & 780000 & 721000 & 724800 \\
\hline Dead wood species (\% and [ha]) & $5[54]$ & $10[5774]$ & $5[54]$ & $10[1530]$ & $5[527]$ \\
\hline Species with poor dispersal (ha) & 54 & 1655 & 54 & 1097 & 572 \\
\hline Accessibility (\% and [ha]) & $5[0]$ & $10[0]$ & 5 [7389] & $10[510]$ & 5 [2896] \\
\hline Clear-cut area (ha) & 680 & 655 & 600 & 625 & 645 \\
\hline Recreational areas (ha) & 0 & 0 & 1448 & 494 & 939 \\
\hline
\end{tabular}

2.2. The EGP models were formulated and solved with LINGO software.

\section{Consensus Rankings}

The individual preferences were aggregated into a collective preference using different approaches: the WAMM, GMM, and EGP. The stakeholder weights were applied when using the WAMM and EGP. This subsection presents the consensus rankings of alternatives determined using the different approaches for aggregation. The stakeholders' individual criteria weights are not presented here, but it is noted that the AHP and EGP produced criteria weights that were similar.

One ranking was obtained for the reference group that jointly made the pairwise comparisons and seven consensus rankings were determined for the group that made the pairwise comparisons individually (Table 2). One ranking was obtained using the GMM. Two similar rankings were obtained using the WAMM: one ranking with equal weights for all stakeholders and one with weights determined by the stakeholders. Four somewhat different rankings were obtained by EGP; two rankings with equal weights for all stakeholders and two with weights determined by the stakeholders.

Plan C, the "recreation" alternative, had the highest rank in all but two of the consensus rankings. When EGP is used with $\lambda=0, \mu=0$, and $p=\infty$, plan D (the first "mixed" alternative) is ranked first in the case of different stakeholder weights and plan E (the second "mixed" alternative) is ranked first when stakeholders have equal weights. The result of the group preference approach is that plans $\mathrm{C}$ and $\mathrm{D}$ tie for first place and plan A is a very close third.

\section{DISCUSSION}

Plan C, the "recreation" alternative, obtains the highest rank in all but two of the consensus rankings. The reason for this seemed to be that the tourism entrepreneur and the representative for sport and outdoor life, for both of whom recreation was a main interest, were given large weights of influence (0.18 and 0.19). Plans D and E, the "mixed" alternatives, attained the highest rank using EGP with a minority perspective $(\lambda=0, \mu=0$, and $p=\infty)$ with different and equal stakeholder weights respectively. This illustrates the balancing effect of the minority perspective, because plan 
Table 2. Consensus Rankings of the Alternatives A-E Obtained Using the Different Methods

\begin{tabular}{|c|c|c|c|c|c|c|}
\hline Alternative & & $\mathbf{A}$ & B & $\mathbf{C}$ & D & $\mathbf{E}$ \\
\hline \multicolumn{2}{|c|}{ Group preference approach } & $3(0.22)$ & $4(0.17)$ & $1(0.23)$ & $1(0.23)$ & $5(0.15)$ \\
\hline \multicolumn{2}{|l|}{ GMM } & $5(0.12)$ & $2(0.19)$ & $1(0.34)$ & $3(0.18)$ & $4(0.17)$ \\
\hline \multirow[t]{2}{*}{ WAMM } & Different stakeholder weights & $3(0.18)$ & $5(0.15)$ & $1(0.30)$ & $2(0.22)$ & $4(0.16)$ \\
\hline & Equal stakeholder weights & $5(0.15)$ & $3(0.17)$ & $1(0.31)$ & $2(0.21)$ & $3(0.17)$ \\
\hline \multirow[t]{6}{*}{ EGP } & Different stakeholder weights & & & & & \\
\hline & $\lambda=1, \mu=1, p=1$ & 2 & 5 & 1 & 4 & 2 \\
\hline & $\lambda=0, \mu=0, p=\infty$ & 2 & 5 & 4 & 1 & 3 \\
\hline & Equal stakeholder weights & & & & & \\
\hline & $\lambda=1, \mu=1, p=1$ & 4 & 5 & 1 & 3 & 2 \\
\hline & $\lambda=0, \mu=0, p=\infty$ & 4 & 4 & 2 & 2 & 1 \\
\hline
\end{tabular}

The rankings range from 1 to 5 , where 1 is the highest rank and 5 is the lowest rank. Values within parentheses are the weights for each alternative for the group preference approach, the GMM, and WAMM (the larger the value, the higher ranked is the alternative). The rankings for the EGP approach is given by the displacement from the ideal (the lower the value, the higher ranked is the alternative); these numbers are not comparable with the weights and to avoid confusion they are not included in the table.

$\mathrm{D}$ is in fact a compromise solution between timber production, biodiversity and, to some extent, recreation while plan $\mathrm{E}$ is a compromise between timber production, recreation and, to some extent, biodiversity.

The above results can be compared with those of the group preference approach. Using the reference approach, plans $\mathrm{C}$ and $\mathrm{D}$ tie for first place and plan $\mathrm{A}$ is a very close third. In their discussions of this result, the group agreed that they jointly preferred plan D based on what they had learnt about the alternatives and the group members' preferences in the process. That using EGP with minority perspective and with stakeholder weights produced the same winner as the group preference approach could indicate that the minority perspective, where the displacement of the worst-off individual from the consensus solution is minimized, has some likeness to the process of mutual learning taking place in the group preference approach.

Thus, in line with the theoretical framework the results of this study indicate that EGP could be an interesting aggregation approach to use in participatory planning because of the extra dimension that provides the possibility to obtain both majority consensus solutions and balanced solutions that minimize the displacement of the worst-off individual from the consensus solution [39]. Thus, the minority perspective of EGP could be useful for finding balanced consensus solutions that are not determined exclusively by the weight of influence assigned to each stakeholder. The role of parameters $\lambda=0$ and $\mu=0$ is to minimize the greatest deviation and thereby balance the solutions. For example, when Model 2 is applied, the effect of $\mu=0$ is that the aggregated criteria weights that are obtained are balanced in the sense that they are, as far as possible, at the same distance from the criteria weights of each of the individual stakeholders. This is a solution to the advantage of the individual with the most displaced preferences with respect to the majority [32]. This property can be desirable in politically sensitive situations or situations where stakeholders have very diverging values. In contrast, employing EGP with $\lambda=1, \mu=1$, and $p=1$, we obtain a majority perspective that produces rankings similar to those obtained using the GMM and WAMM. When EGP employs a majority perspective, the aggregated preference is the (weighted) median of the individual preferences [33]. When individual preferences are aggregated using the WAMM or GMM, the result is the mean of the individual preferences. That the WAMM, GMM, and EGP with majority perspective all produce the same winner and similar rankings should perhaps not be unexpected as they all identify some kind of average of the preferences.

Consensus rankings could potentially also be determined for intermediate values of $\lambda$, signifying compromise solutions between the majority and minority perspectives. In this study, we chose to focus on the extreme values to not confuse the comparisons with the other methods. However, in a real planning situation these intermediate solutions may provide very interesting compromises.

Compared to WAMM and GMM, EGP may be a timeconsuming and difficult approach for the analyst because there is presently no software that can process data automatically, like there is for the AHP (e.g., ExpertChoice and WEB-Hipre). The analyst will need a basic knowledge of linear programming and software for linear optimization. To construct the EGP models from scratch will take some time; if the models have been used previously, albeit for another problem, this task will be easier. Another issue with using EGP in a participatory process is the pedagogical problem of how to present the approach to the stakeholders. As the models are rather advanced, they should not be presented as they are. Methods for how to convey the meaning of the majority and minority perspectives, e.g., by illustrating the principles visually, need to be developed. For the analyst, the group preference approach would seem to be the quickest and easiest because no aggregation calculations have to be made. However, in a situation with real stakeholders with conflicting interests, a facilitator would probably be needed.

The case study raised some additional methodological issues not directly related to the actual aggregation approaches but rather to the use of MCDA in a participatory process. When using the GMM and WAMM many pairwise 
comparisons had to be made, making the procedure time consuming and cognitively demanding for the students. This is because the standard form of AHP that was used requires stakeholders to make pairwise comparisons of both criteria and of alternatives with respect to each criterion, which in total sum up to quite a large number of comparisons. However, to avoid a too burdensome comparison procedure, AHP could be modified and used in combination with other methods. One option is to define a value function for each criterion that assigns weights to the alternatives according to these functions, similar to the procedure used for EGP in step 3, equation (16). Another option could be to use regression analysis to reduce the number of comparisons needed [44]. In this case study, EGP facilitated the judgment process in terms of both time and effort because the stakeholders did not have to make pairwise comparisons of alternatives for different criteria. For the procedure of step 3, we have made two important assumptions (see section on EGP): (i) that the value functions are linear and (ii) that the range for each criterion is local. Both these assumptions are potentially problematic. To assume that the value functions are linear is a simplification of a reality where many criteria may have nonlinear value functions [20]. The range of a criterion will affect the final result and might have affected the stakeholders' preferences for the criteria because the importance assigned to a criterion is very probably dependent on the range considered for that criterion [45].

The experimental approach used in this study has some limitations. The role-play does not mimic a situation with real stakeholders perfectly. This could, for instance, have made it easier for the students employing the group preference approach to compromise because their real interests were not at stake. The students may have fewer problems with MCDA because they have better background knowledge than the average "real" stakeholder, and making judgments may be easier for the students because of their specialist forestry education.

One conclusion of this study is that the aggregation approaches have different properties and provide different rankings. That the approaches produce different results is neither surprising, nor a problem; no result should be regarded as more truthful than another and the differences are consequences of the properties of the different methods [46]. Moreover, if MCDA and aggregation methods are used in participatory planning, these methods should be presented and used in such a way that it is clear that they are tools for exploring and increasing knowledge about the issue rather than infallible methods that produce "the right solution"; that is, a process-oriented rather than an outcome-oriented perspective have to be applied [13]. The choice of aggregation approach should be adapted to the situation at hand and, furthermore, should be accounted for and explained to the stakeholders. This may prove to be a considerable pedagogical problem; though it may not be possible to explain the aggregation method in full detail, at least the underlying logic should make sense to stakeholders. We hope that this case study will provide useful guidelines for choosing an aggregation approach in situations where MCDA is applied within a participatory process. Future research should be aimed at real planning cases where stakeholders are included in the evaluation of properties and results of different aggregation approaches.

\section{ACKNOWLEDGEMENTS}

Funding for this study was provided by Stiftelsen Skogssällskapet (The Swedish Forest Society Foundation).

\section{CONFLICT OF INTEREST}

The authors confirm that this article content has no conflict of interest.

\section{REFERENCES}

[1] Diaz-Balteiro L, Romero C. Making forestry decisions with multiple criteria: A review and an assessment. For Ecol Manage 2008; 255: 3222-41.

[2] Ananda J, Herath G. Incorporating stakeholder values into regional forest planning: a value function approach. Ecol Econ 2003; 45: 75-90.

[3] Ananda J, Herath G. The use of Analytic Hierarchy Process to incorporate stakeholder preferences into regional forest planning. For Policy Econ 2003; 5: 13-26.

[4] Hiltunen V, Kangas J, Pykäläinen J. Voting methods in strategic forest planning -- Experiences from Metsähallitus. For Policy Econ 2008; 10: 117-27.

[5] Hiltunen V, Kurttila M, Leskinen P, et al. Mesta: An internet-based decision-support application for participatory strategic-level natural resources planning. For Policy Econ 2009; 11: 1-9.

[6] Kangas A, Kangas J, Pykäläinen J. Outranking methods as tools in strategic natural resources planning. Silva Fenn 2001; 35: 215-27.

[7] Laukkanen S, Palander T, Kangas J. Applying voting theory in participatory decision support for sustainable timber harvesting. Can J For Res 2004; 34: 1511-24.

[8] Maness T, Farrell R. A multi-objective scenario evaluation model for sustainable forest management using criteria and indicators. Can J For Res 2004; 34: 2004-17.

[9] Pykäläinen J, Hiltunen V, Leskinen P. Complementary use of voting methods and interactive utility analysis in participatory strategic forest planning: Experiences gained from western Finland. Can J For Res 2007; 37: 853-65.

[10] Pykäläinen J, Kangas J, Loikkanen T. Interactive decision analysis in participatory strategic forest planning: Experiences from state owned Boreal forests. J For Econ 1999; 5: 341-64.

[11] Sheppard SRJ, Meitner M. Using multi-criteria analysis and visualisation for sustainable forest management planning with stakeholder groups. For Ecol Manage 2005; 207: 171-87.

[12] FAO/ECE/ILO. Public participation in forestry in Europe and North America. Synopsis of the report of the FAO/ECE/ILO joint committee team of specialists on participation in forestry Vienna. MCPFE Paper 2. Vienna: Ministerial Conference on the Protection of Forests in Europe, Liaison Unit Vienna 2002.

[13] Mendoza GA, Martins H. Multi-criteria decision analysis in natural resource management: A critical review of methods and new modelling paradigms. For Ecol Manage 2006; 230: 1-22.

[14] Nordström E-M, Eriksson LO, Öhman K. Integrating multiple criteria decision analysis in participatory forest planning: Experience from a case study in northern Sweden. For Policy Econ 2010; 12: 562-74.

[15] Rauschmayer F, Wittmer H. Evaluating deliberative and analytical methods for the resolution of environmental conflicts. Land Use Policy 2006; 23: 108-22.

[16] Phillips RA. Stakeholder theory and a principle of fairness. Bus Ethics Q 1997; 7: 51-66.

[17] Munda G. Social multi-criteria evaluation: Methodological foundations and operational consequences. Eur J Oper Res 2004; 158: 662-77.

[18] Belton V, Pictet J. A framework for group decision using a MCDA model: Sharing, aggregating or comparing individual information? J Décis Syst 1997; 6: 283-303.

[19] Ananda J. Implementing participatory decision making in forest planning. Environ Manage 2007; 39: 534-44.

[20] Kangas J, Loikkanen T, Pukkala T, et al. A participatory approach to tactical forest planning. Acta For Fenn 1996; 251: 1-24.

[21] Saaty TL. The analytic hierarchy process: planning, priority setting, resource allocation. $2^{\text {nd }}$ ed. Pittsburgh: RWS Publications 1990. 
[22] Ananda J, Herath G. A critical review of multi-criteria decision making methods with special reference to forest management and planning. Ecol Econ 2009; 68: 2535-48.

[23] Ananda J, Herath G. Multi-attribute preference modelling and regional land-use planning. Ecol Econ 2008; 65: 325-35.

[24] Kangas J. An approach to public participation in strategic forest management planning. For Ecol Manage 1994; 70: 75-88.

[25] Hajkowicz SA, McDonald GT, Smith PN. An evaluation of multiple objective decision support weighting techniques in natural resource management. J Environ Plan Manag 2000; 43: 505-18.

[26] Ramanathan R, Ganesh LS. Group-preference aggregation methods employed in AHP - an evaluation and an intrinsic process for deriving members weightages. Eur J Oper Res 1994 Dec; 79: 24965.

[27] Forman E, Peniwati K. Aggregating individual judgments and priorities with the Analytic Hierarchy Process. Eur J Oper Res 1998; 108: 165-9.

[28] Van Den Honert RC, Lootsma FA. Group preference aggregation in the multiplicative AHP The model of the group decision process and Pareto optimality. Eur J Oper Res 1997; 96: 363-70.

[29] Bryson NKM, Joseph A. Generating consensus priority point vectors: A logarithmic goal programming approach. Comput Oper Res 1999; 26: 637-43.

[30] Cho Y-G, Cho K-T. A loss function approach to group preference aggregation in the AHP. Comput Oper Res 2008; 35: 884-92.

[31] Escobar M, Moreno-Jiménez J. Aggregation of individual preference structures in ahp-group decision making. Group Decis Negotiation 2007; 16: 287-301.

[32] González-Pachón J, Romero C. Inferring consensus weights from pairwise comparison matrices without suitable properties. Ann Oper Res 2007; 154: 123-32.

[33] Linares P, Romero C. Aggregation of preferences in an environmental economics context: a goal-programming approach. Omega 2002; 30: 89-95.

[34] Diaz-Balteiro L, Gonzalez-Pachon J, Romero C. Forest management with multiple criteria and multiple stakeholders: An application to two public forests in Spain. Scand J For Res 2009; 24: 87-93.

[35] Nordström E-M, Romero C, Eriksson LO, et al. Aggregation of preferences in participatory forest planning with multiple criteria: an application to the urban forest in Lycksele, Sweden. Can J For Res 2009; 39: 1979-92.
[36] Saaty TL. A scaling method for priorities in hierarchical structures. J Math Psychol 1977; 15: 234-81.

[37] Ignizio JP, Romero C. Goal programming. In: Hossein B, Ed. Encyclopedia of information systems. New York: Elsevier 2003; pp. $489-500$

[38] Diaz-Balteiro L, Romero C. Combined use of goal programming and the Analytic Hierarchy Process in forest management. In: Schmoldt DL, Kangas J, Mendoza GA, et al, Eds. The Analytic Hierarchy Process in natural resource and environmental decision making. Dordrecht: Kluwer Academic Publishers 2001; pp. 81-95.

[39] Nordström E-M, Öhman K, Eriksson Ljusk O. Approaches for aggregating preferences in participatory forest planning: An experiment with university students. In: Anderssen RS, Braddock RD, Newham LTH, Eds. 18th World IMACS Congress and MODSIM09 International Congress on Modelling and Simulation. Modelling and Simulation Society of Australia and New Zealand and International Association for Mathematics and Computers in Simulation 2009; pp. 2864-70.

[40] Yu PL. A class of solutions for group decision problems. Manage Sci 1973; 19: 936-46.

[41] André FJ, Romero C. Computing compromise solutions: On the connections between compromise programming and composite programming. Appl Math Comput 2008; 195: 1-10.

[42] Nordström E-M, Öhman K. Mångbruksplan för lyckseles tätortsnära skog: en tillämpning av deltagande planering och flermålsanalys. Report no. 267. Umeå: Department of Forest Resource Management, Swedish University of Agricultural Sciences 2010

[43] Keeney RL. Value-focused thinking - a path to creative decision making. Cambridge: Harvard University Press 1992.

[44] Alho JM, Kolehmainen O, Leskinen P. Regression methods for pairwise comparison data. In: Schmoldt DL, Kangas J, Mendoza GA, et al, Eds. The Analytic Hierarchy Process in natural resource and environmental decision making. Dordrecht: Kluwer Academic Publishers 2001; pp. 235-51

[45] von Winterfeldt D, Edwards W. Decision analysis and behavioral research. Cambridge: Cambridge University Press 1986.

[46] Kangas J, Kangas A, Leskinen P, et al. MCDM methods in strategic planning of forestry on state-owned lands in Finland: applications and experiences. J Multi-Criteria Decis Anal 2001; 10: $257-71$.

(C) Nordström et al.; Licensee Bentham Open.

This is an open access article licensed under the terms of the Creative Commons Attribution Non-Commercial License (http://creativecommons.org/licenses/by$\mathrm{nc} / 3.0 /$ ) which permits unrestricted, non-commercial use, distribution and reproduction in any medium, provided the work is properly cited. 